\title{
Design thinking models for architectural education
}

\author{
Bojan Tepavčević \\ University of Novi Sad, Serbia \\ Faculty of Technical Sciences, Department of Architecture and Urban Planning \\ tepavcevicb@uns.ac.rs
}

\begin{abstract}
Technology advancements have profound impact on design thinking in architecture, professional practice and architectural education. New models of representation, along with computational design thinking and innovative approaches in digital fabrication bring new demands for the rethinking of educational pedagogy for the new generation of architects in the digital age. While learning by making has been deeply rooted in the process of architectural education, digital modes of design, representation and manufacturing reconcile the dual nature of design process that has traditionally oscillated between drawing and making, visual and material. In this paper, the relationship between making process in design-led research and other aspects that challenge architectural education are analysed and described. Along with emerging trends in this topic, current design-led research position and strategies at some Australasia schools of architecture are presented.
\end{abstract}

Keywords: learning by making, model making, place making, live projects, architectural education.

\section{To cite this article:}

Teparčević, B. (2017). Design thinking models for architectural education. The Journal of Public Space, 2(3), Special Issue, 67-72, DOI: I0.5204/jps.v2i3.II5

This article has been peer-reviewed and accepted for publication in The Journal of Public Space. Please see the Editorial Policies under the 'About' section of the journal website for further information.

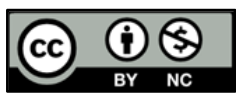

This work is licensed under a Creative Commons Attribution - Non Commercial 4.0 International License https://creativecommons.org/licenses/by-nc/4.0/ 


\section{Introduction}

Technology advancements are challenging traditional models of architectural design and education in the age of digital communication. Computational design thinking, along with digital tools for analysis of building performance, geometric optimization of free form structures, novel approaches to digital manufacturing and fabrication, proliferation of new materials, bring higher levels of complexity in the field of architecture, as well as new demands for architectural professional practice. Such demands call for a big rethink of education pedagogy for future architects based on producing "collaborators", rather than "solitary genius" architects (Buchanan 2012), who are able to work in an interactive environment with an array of consultants in multidisciplinary design teams. The need for creation of new and reconstruction of existing pedagogical models in architectural education emerged from new theoretical, computational and cognitive approaches (Oxman 2008). While some authors reconsider the traditional role of model making in architecture fostered with digital fabrication (Stavric et al 2013, Duarte et al $20 \mathrm{II}$ ), other considered data visualization and architectural representation as a foundation for educational models in architecture (Bermudez and Agutter, 2005).

Model based and representation based design thinking models have been crucial for the development of pedagogical approaches in architectural education. This paper analyses and discusses the evolution of two approaches of design thinking (model based and representation based) and their role in the development of pedagogical models for architectural education in digital age. The relationship between the making process in design-led research and other aspects that challenge architectural education, such as new education paradigms and new digital design environments, are described. Additionally, this paper presents current educational experiments in Architecture Schools of Australasia as a pedagogical framework for educational strategies related to this topic.

\section{Evolution of model based design thinking in architecture}

Learning by making has been deeply rooted in the live process of architectural design. From "tektons", ancient Greek builders, to contemporary “digital master builders", material experimentation and model making have had an important role in the design process. Physical realisation of design concepts has served as a learning platform for testing structural, tangible and visual properties of materials. The most celebrated Renaissance inventions in architectural representation: perspective and simultaneous correspondence between orthographic projections, bring historical disassociation in the design process between visual and material, academic (intellectual) and crafted, imagined and built. However, model making has been proven to have an important role in gaining knowledge, skills and architect's intuition in the design process until today, which can be confirmed by some examples of twentieth-century legacy of architectural innovation through design-led research. In that sense, Antoni Gaudi, Heinz Isler and Frei Otto utilize physical models to explore a parametric, structurally informed design process, which led to highly complex, but elegant solutions in architectural design. Furthermore, wire models of the Chapel at Ronchamp or string models of the Brussels pavilion served to Le Corbusier to explore the relationship between mathematical and physical representation of geometrically rationalized design solutions. In a similar way, modern architects used a model to explore visual and tangible properties of materials. Mies van der Rohe mastered visual and reflective qualities of glass as a material through the process of making a scale model for Friedrichstrasse tower in 1917. Similarly, Peter Zumthor or Herzog \& de Meuron used models and full scale prototypes in order to explore tangible properties of materials.

Unfortunately, there are not too many examples of model-making experiments and realizations, pertaining to Learning-by-Making approach in the legacy of modern and contemporary 
architecture. The above mentioned examples do not represent common practice in the designled research process. In most of cases, models are used only as tools for representation. We can find many reasons why design by making was not a common research practice and educational methodology. Compared to the visual representation approach, making models and full scale prototypes is, in most cases, a time consuming, tedious or expensive way to explore complex relations between material, form and structure. Visual tools for geometric representation are also used as a way of communication between an architect and a contractor, which additionally increases the gap between academic research and professional practice.

However, the digital age has not only brought revolution in geometric modelling and representation of space, but also reconciliation of designing and making in architecture. "Digital turn" in architecture brings us the new tools that enable creation of forms that could not have been designed without them, releasing the imagination of architects to unprecedented solutions, but also re-questions awareness towards material properties and making/manufacturing processes (Carpo 2013). Digital manufacturing and increasing advances in material science have radically affected architectural thinking toward digital tectonics, (Leach et al. 2004) a new materialbased design in which material properties, manufacturing technology and digital design processes are fully integrated.

\section{Design thinking through visual representation and new notions of space in digital environments}

Being a part of another tradition of architectural thinking, visual imagination has been assisted through various modes of architectural representation. With the advent of digital technologies, notion of space in architecture, which traditionally relied on sensory and existential characteristics, has been developing in new directions. One of the directions deals with geometric properties of space, while another with its social and cognitive aspects.

New geometric concepts of space, different from the three-dimensional Euclidean space, have had an impact on architecture and design thinking in the past two decades (Tepavcevic, 2014). A growing interest toward a non-metric concept of space, such as topological space, has been influenced by development of digital design tools. Recognizing the impact of motion-based modelling tools in CGI software, Greg Lynn was one of the first architects who connected continuous transformations of curvilinear forms with the notion of topology in architecture (Lynn 1993). Topology, a branch of mathematics which deals with those problems that do not depend on the exact shape, can be defined as a study of qualitative properties of certain objects such as convergence, connectedness and continuity which remains unchanged after undergoing a certain kind of transformation. In other words, in digital design process the shape, size or distance are not relevant, but their parametric definition (homeomorphism) and connection between elements. In that sense, virtual environments can provide disjunction from traditional, Cartesian logic of thinking about representation of space in architecture. New digital design tools, along with new digital display devices, from smart phones and tablets to head mounted devices, provide new territory for creating interactive worlds based on fusion of digital and virtual world. Virtual and augmented reality challenges the concept of space providing users with immersive, interactive experience fed by computer generated data.

From the standpoints of social and cognitive science, human activities in the web environment open new directions for new ideas and speculations about space and place in the built environment. Making places that serve diverse human activities was common practice for architects, landscape architects and urban planners for centuries.

Throughout the history, public spaces in built environments have been used as places for meetings, trade and traffic. Public spaces were crucial for the life of cities. However, in 
contemporary society, many activities that were traditionally connected to public spaces, such as meeting or shopping, are connected with other types of spaces as well. According to Marc Augé, in our supermodern society, which is filled with "overabundance of events", there are many "nonplaces" with thin and abstract identity" (Augé 1995). Augé recognized spaces of travel, consumption and exchange such as shopping malls, airports, retail outlets, hotel rooms and motorways as common examples of "non-places", spaces which cannot be defined as relational, or historical, or concerned with identity.

According to Canter, place-making can be defined as a conscious process of arranging objects and spaces to create an environment that supports desired activities, while conveying the social and cultural conceptions of the actors and their wider communities (Canter 1977). In that sense, cyberspace, a metaphor of virtual environment for broad range of everyday economic, cultural, and other human activities, is also concerned with the notion of place and space. Those new "digital places" in virtual environments are deprived of identity based on genius loci, but they are linked with users' activities and their connections. Moreover, analyses of human activities within web environments and their relation with real physical spaces can provide invaluable information about condition of public spaces and places with abstract identities (non-places) in the digital age.

\section{Pedagogical models for digital design thinking in architecture}

According to Dewey, there are two sources of knowledge for an individual: one is goal directed and the other acquired from student interaction with the environment (Dewey 1938). Both sources represent a framework for a maker-centered education. Making scale models and prototypes, which is crucial for Learning-by-Making (LBM) approach, is connected with experiential learning and is based on Jean Piaget's epistemological theory of constructivism (Cakir 2008). In this sense, the learning process in architectural design is the most efficient through hands-on material engagement. While seeking new models for the architectural education which is exposed to extreme complexity of aesthetical, ethical, technical, economical, functional challenges, maker-centered education tries to connect the processes of design and construction. As an educational model, LMB has been deeply rooted in the history of architecture, but it has always been in the process of adjustment to new cultural and technological demands. Throughout the centuries, learning architectural skills has been tightly connected with hands-on material and construction experimentation. During the renaissance, paper-based design thinking (PDT) has been developed and became important part of the design process. In the $X X$ century, the most prominent pedagogical models in architecture were based on the principles of the Bauhaus "Vorkurs". They were essential for the elementary study of form and material, largely based on workshop activities with hands-on activity of doing and making. With the advent of digital technologies and tools, the need for the development of novel LMB approaches emerged. Continuation and development of LMB and PDT in the digital age can be analysed through new educational theories, educational models (live projects), and educational techniques. Some successful examples of utilization of new educational models and theories from the Australasia school of architecture are further analysed within this section.

\section{I Analysing learning outcomes from the $L M B$ approach in architecture}

"Learning" architectural design is a complex process in which students experience transformation of their understanding of the process of design. Threshold concept is a relatively new theoretical framework for teaching based on overcoming student's learning barriers by understanding the following dimensions of learning: transformative, bounded, integrative, discursive and troublesome. It involves integrating or synthesising knowledge that was previously viewed as unrelated (Meyer and Land, 2006 ). Threshold concepts bind a subject together, being 
fundamental to ways of thinking and practising in a discipline. It can be applied to any discipline in higher education, but it is of particular importance for education in architecture where aesthetic, tactile experience is crucial, and creative practice is a way of thinking and a way of understanding (Hokstad et al 2016). In order to analyse educational outcomes from the learning experience of LMB studio at the School of Architecture \& Design, University of Tasmania, Richard Burnham and Louise Wallis used educational theory called threshold concepts (Meyer and Land, 2006). They have been analysed at the LMB studios in 2013 and 2014 in relation to the most common characteristics attributed to threshold concepts. As a result, Burnham and Wallis identified that the learning experience of an LBM studio is closely aligned with the transformative, bounded, integrative, discursive and troublesome characteristics of a Threshold concept.

\section{2. $L M B$ approach to the non-standard building forms}

One of the most important issues for the design of non-standard building forms is efficient and feasible realisation. While complex forms can be easily created in digital environment, fabrication and manufacturing might be a challenge and they require a structurally informed and fabricationaware design process. For that reason, deep understanding of material behaviour and structural properties, along with collaborative design environment and interdisciplinary overlap are crucial for the design process and expansion of design knowledge.

Digital fabrication strategies and learning-by-making approach provide interesting possibilities and new territories for the research in architecture, as well as design pedagogy. Understanding of formal qualities and structural properties of the material are central to the live design-led research and construction of a bamboo pavilion for the Dark Mofo annual arts festival in Hobart, Tasmania. This experimental project was developed through collaboration between the School of Architecture \& Design at the University of Tasmania and Sydney-based architectural practice Cave Urban. Direct engagement of students in the process of design and practice was done in a collaborative environment that included bamboo-engineering specialists, practicing artists and event designers. Experimentation with full scale prototypes and scale models in the design process, which is crucial for Learning-by-Making (LBM) stream at the University of Tasmania's architecture curriculum, is used to explore formal qualities and structural behaviour of nonconventional materials and construction processes. Through the development of prototypes for formal testing of design ideas and construction, the understanding of structural performance and material properties is also provided. In that sense, LMB approach can be observed not only as a design methodology shown in the experimental bamboo pavilion project, but also educational and pedagogical methodology in architecture, as suggested by Burnham and Wallis.

\subsection{Live projects- practice based LMB approach}

Dissociation between architects and other parties in the building process started in late renaissance and culminated in the mid nineteenth century with the advent of "contract" documents (Kolarevic 2005). It also affected architectural education system, creating the discrepancy between architectural academy, professional practice and market. Consequently, live projects emerged as a new pedagogical form, based on LMB approach bringing closer the academy, profession, market and society. Such discrepancy between architectural academy, the profession and the market is in the main focus of the research about "live project" within the design studio at the School of Architecture and Planning, University of Auckland, conducted by Michael Davis. Building contractors and developers are often reluctant to take part in speculative and experimental projects with complex forms, found in design studios in many architecture schools worldwide. Moreover, academy is often seen as being cut off from reality and pragmatic engagements regarding the economic and social demands. The aim of the live project is closer 
connection between academy and the profession, through engagement of market conditions. According to Davis, bringing together community groups, businesses and developers to live design studio projects, along with collaborative process, may result in negotiated, speculativeyet-realisable projects. Introducing live projects in architectural education brings new opportunities to engage a diverse range of stakeholders, as well as consultants and experts, in a creative learning process through collaborative team work. At the same time, live projects recall maker-centered learning in architecture.

\subsection{Pedagogical models for the emerging digital design environments}

Along with Learning-by-making, paper-based design thinking is essential for the process of learning and thinking in design. Characterization of paper-based design thinking as a foundation of design education became broadly accepted (Schön and Wiggins 1988, Oxman 2008) and introduction of CAD (computer-aided design) did not bring revolution in the process of design thinking. While CAD has been basically considered as a tool for imitating paper-based design, DAD (digital-architectural design) brings novel concepts of digital design models (Kalay 2004), new design thinking (Oxman 2017) and new notions of space (Teparčević 20I4), replacing the paper based media approach.

In other words, digital design environment brings not only new design tools, but also a new way of design thinking and notion of space. In that way, digital environment opens up the question of designing spaces in architecture characterized by the duality of physical and digital worlds. For Uwe Rieger and The Lab for Digital Spatial Operations [arc/sec] at the University of Auckland, the main research question is about user interaction with haptic-digital spaces and the possibilities for construction and design of buildings in which digital information can be given a physical form and physical and spatial appearance. Design process focused on user interaction provides new territories for research in which the boundaries between physical and digital world are blurred.

At the same time, digital environment opens up the question of design representation. New modes of design representation emerged from digital media, enabling visualisation of different kinds of data. Data visualization became extremely important for GIS and geospatial representation in urban planning. This can be exemplified by the study conducted by Manfredini, lenner and Litterick at the University of Auckland. The social network platform Instagram, which provides geospatial information and visual representation of space, is used in their research to analyse spatial qualities of shopping malls in Auckland in order to show a strong relationship between spatial identity and number of images that represent that space. This research gives valuable contribution to the research of places of with abstract identities (non-places) and how are they perceived by users. Such researches are of particular importance for designing public spaces and improving conditions of public life.

\section{Conclusion}

Models of design thinking in architecture have traditionally oscillated between drawing and making, visual and material. Advanced design and manufacturing technologies, along with digital modes of representation, did not only bring design thinking models, but also reconciled the dual nature of the design process. Furthermore, rethinking of models for design-led research provides a new framework for design pedagogy that responds to technological shifts and new design thinking. The experience of engagement within the framework of live projects offers new educational trajectories that lean on collaborative research setting and maker-centered learning processes in architecture. 